\title{
Stability and reliability of low voltage hybrid AC-DC microgrids power flow model in islanding operation
}

\author{
Hasti Afianti ${ }^{1}$, Ontoseno Penangsang ${ }^{2}$, Adi Soeprijanto $^{3}$ \\ ${ }^{1,2,3}$ Department of Electrical Engineering, Institut Teknologi Sepuluh Nopember Surabaya, Indonesia \\ ${ }^{1}$ Engineering Faculty, University of Bhayangkara Surabaya, Indonesia
}

\begin{tabular}{l} 
Article Info \\
\hline Article history: \\
Received Nov 21, 2019 \\
Revised Jan 14, 2020 \\
Accepted Feb 4, 2020 \\
\hline Keywords: \\
Converter non linear load \\
Distribution interlinking \\
Hybrid AC- DC \\
Islanding operation \\
Microgrid low voltage
\end{tabular}

Corresponding Author:

Hasti Afianti,

Engineering Faculty,

University of Bhayangkara Surabaya.

Ahmad Yani 114, Surabaya, Indonesia.

Email: hasti_afianti@ubhara.ac.id

\begin{abstract}
The problem of decreasing and increasing power flow in hybrid AC-DC microgrids in islanding operations is the concern of this study. This condition arises if one sub-microgrid cannot supply load power requirements, either because of a decrease in power at the source or an increase in load on the sub-microgrid network. The result, in this study using a bidirectional converter as an interlinking converter, the converter can change the power flow from ac sub microgrid to dc sub microgrid and vice versa. With this converter, load requirements can be met despite a lack of power in one of the sub microgrids. The simulations in this study are supported by Simulink / Matlab software. This model is built in a low voltage system, and power flow analysis is in steady state with two different cases. Simulation results show the stability and reliability of power flow in both sub microgrids with stable frequency and voltage when power and load changes occur.
\end{abstract}

Copyright $\odot 2020$ Institute of Advanced Engineering and Science. All rights reserved.

\section{INTRODUCTION}

Technological advances in the use of Renewable Energy Sources (RES) have increased [1-2]. The application is flexible, especially in remote areas where there is no electricity grid, but renewable energy sources are abundant [3-4]. The one which popular is PV systems, which naturally produce DC power. Meanwhile, at present, many devices use DC sources, for example, Light Emitting Diode (LED) for lights, computers, and others. So it will be more efficient if the equipment that requires DC power is connected to the DC source directly without going through the converter. Furthermore, the construction of DC microgrids, which connect DC sources and DC loads directly, will reduce the use of converters [5-6]. Recently DC distribution systems or DC microgrids are also developing [7]. In addition to the use of RES which naturally produces DC power, there are several RES that produces AC power such as wind, micro-hydro, etc. And equipment that requires AC power is certainly more varied. so that currently the construction of an $\mathrm{AC}$ microgrid is also still being done.

The combination of AC and DC microgrids is an effective way of using RES in remote are as because the natural resources generated can be either AC or DC power. Hybrid AC-DC microgrid is a microgrid that combines DC and AC sub microgrid, both sub microgrids are connected by an interlinking converter [6, 8-9]. The advantages of hybrid AC-DC microgrids, in general, can be summarized as follows[5-6, 8-13]: Increase installed power capacity; reducing the use of power electronic equipments: converter, Power Factor Correction (PFC); improve power quality on microgrid AC, because DC load will be directly connected to DC source so that it doesn't cause harmonic pollution. Not only the advantages but also there are weaknesses of this system, one of which is power condition. Uncertain power conditions from 
RES can affect system conditions, especially on islanding conditions. With the various types of sources connected to the system, a good connecting device is certainly needed, in this case, the interlinking converter is expected to be able to regulate the power according to the source conditions and needs of the existing load. A simple converter with ac voltage as the input control has not been able to flow power in both directions properly when there is a change in power and load, but can drain power when a three-phase disturbance occurs [12].

In this paper, a strategy on keeping stability and reliability of the power flow in low voltage hybrid AC-DC microgrid in islanding operations is proposed. Bidirectional converter as interlinking converter is used to connect $\mathrm{AC}$ sub microgrid and DC sub microgrid using input control from two sides of AC and DC sub microgrid, voltage and current from AC sub microgrid and voltage from DC sub microgrid. Simulations have been carried out in two different cases:

1. Power flow from DC to AC sub microgrids

2. Power flow from AC to DC sub microgrids.

The two cases above are also accompanied by a case of load changing on the AC sub microgrid. Power flow analysis is carried out on two sides, AC and DC sub microgrid.

\section{HYBRID AC-DC MICROGRID}

Combining the DC system and the AC system or better known as the hybrid AC-DC microgrid system is a good solution in addressing the current electrical energy needs. In hybrid AC-DC microgrid there are 3 main parts: 1) AC sub microgrids, 2) DC sub microgrids, and 3) interlinking converter that connects AC and DC sub microgrids. Simple power flow in a hybrid AC-DC microgrid is shown in Figure 1. Based on these three components, in the hybrid AC-DC microgrids under islanding conditions there are four operating conditions as explaind in Table 1.

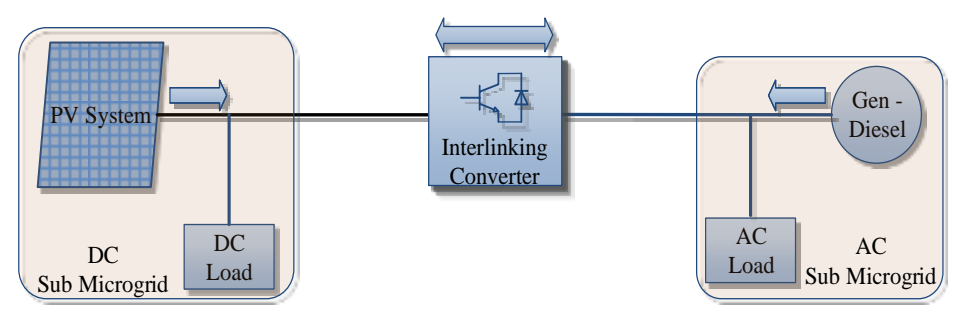

Figure 1. Hybrid AC-DC microgrids

Table 1. Power condition in hybrid AC/DC microgrids [9]

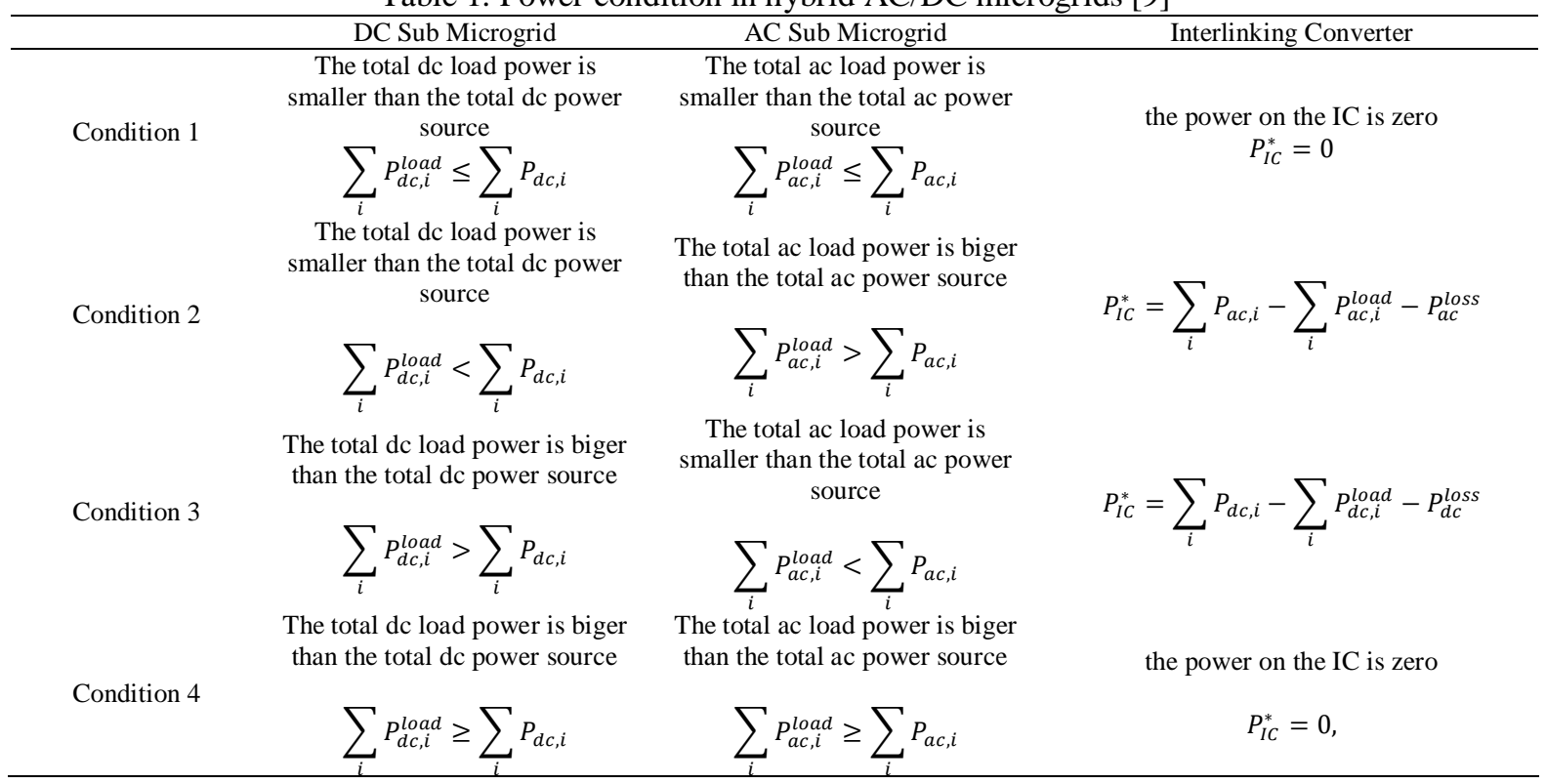


In AC or DC sub microgrid usually there are several sources, whare the notation in Table 1 are $P_{a c, i}$, $P_{d c, i}, P_{a c, i}^{\text {load }}, P_{d c, i}^{\text {load }}, P_{a c, i}^{\text {loss }}, P_{I C}^{*}$ represent the power generated from that source in ac sub microgrid, the DC source in dc sub microgrid, the load power in ac sub microgrid, the load power in dc sub microgrid, the losses contained in the ac sub microgrid and the power flow through the interlinking converter.

\subsection{Power flow in low voltage AC submicrogrids}

Inductance and resistance values in the low voltage line are inversely proportional to the high voltage system, the inductance value in the low voltage line is very small and the resistance value is large. Typical line parameter in grid $\mathrm{R}^{\prime}, \mathrm{X}^{\prime}$ and typical rated current for the high, medium and low voltage line is shown in Table 2 [14-15].

Table 2. Typical line parameter

\begin{tabular}{lccc}
\hline \multicolumn{1}{c}{ Type of Line } & $\mathrm{R}^{\prime}(\Omega / \mathrm{km})$ & $\mathrm{X}^{\prime}(\Omega / \mathrm{km})$ & $\mathrm{R}^{\prime} / \mathrm{X}^{\prime}$ \\
\hline Low Voltage & 0,642 & 0,083 & 7,7 \\
Medium Voltage & 0,161 & 0,190 & 0,85 \\
High Voltage & 0,06 & 0,191 & 0,31 \\
\hline
\end{tabular}

From Table 1 the grid with high voltage has a high inductive value while at medium and low voltage resistive value is higher. This condition indicates that the low voltage system is resistive [16]. The active and reactive power flow at two connected low voltage sources is illustrated in Figure 2, the power flow from generator to a bus is described as [17].

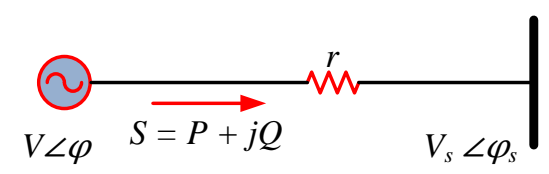

Figure 2. Equivalent circuit in AC sub microgrids

$$
P+j Q=S=V I^{*}=V\left(\frac{V-V_{S}}{r}\right)^{*}
$$

Active and reactive power that flow accros between generator and bus are described as [8]:

$$
\begin{aligned}
& P=\frac{\left|V^{2}\right|}{r}-\frac{|V|\left|V_{s}\right|}{r} \cos \delta \\
& Q=-\frac{|V|\left|V_{S}\right|}{r} \sin \delta \\
& \delta=\varphi-\varphi_{s}=\int\left(\omega-\omega_{s}\right) d t
\end{aligned}
$$

Where $V, \varphi, V_{s}, \varphi_{s}$ are generator voltage amplitude, generator phase angle, bus amplitude voltage, bus phase angle, and $\omega, \omega_{\mathrm{s}}$ are angular frequency of the generator and the bus, respectively, represents the line resistance.

\subsection{Power flow in low voltage $\mathrm{DC}$ microgrid}

In DC sub microgrids, the active power is $[12,18]$ :

$$
P_{d c}=V_{d c} I_{d c}
$$

Where $I_{d c}$ the amount of current coming from all DC sources going to the interlinking converter, and $V_{d c}$ is the voltage in the gate between the DC sub microgrid and interlinking converter. The active power flowed to AC sub microgrids :

$$
P_{g}=P_{d c}-\sum\left(P_{d c-a c}, P_{l c}\right)
$$


Where, $P_{d c-a c}$ is the loss power which due to the conduction and commutation of the converter IGBT, and $P_{l c}$ is the instantaneous power absorbed by the filter. Assuming, there are no power losses in the converter and the filter.

$$
P_{g} \approx P_{d c}
$$

Only active power is transferred to AC sub microgrid:

$$
Q_{g}=0
$$

\subsection{Interlinking converter}

The interlinking converter as interface equipment between the two sub-microgrids requires controls that allow the converter to work in two directions, as an inverter and rectifier, according to the conditions of both sub-microgrids. For this reason, interlinking converters use the bidirectional converter concept.

In Figure 3, the interlinking converter uses three legs with six Insulated Gate Bipolar Transistor (IGBT)s. The input control is come from both sides, in the AC sub microgrid side using current and voltage, and the voltage in the DC sub microgrid side [19-23].

The voltage from the AC sub microgrids become input for the Phase Locked Loop (PLL) circuit before transformed to the d-q coordinate along with the current from the AC sub microgrids. Phase-Locked Loop (PLL) is to equalize the phase angle in the interlinking converter systems. Meanwhile, the Voltage from DC sub microgrids will be compared with the DC reference voltage and controlled with PI controller. The value of the $i_{d \text { reff }}$ depends on the results of the PI control and the constant value which is set as the maximum and minimum values as in (9).

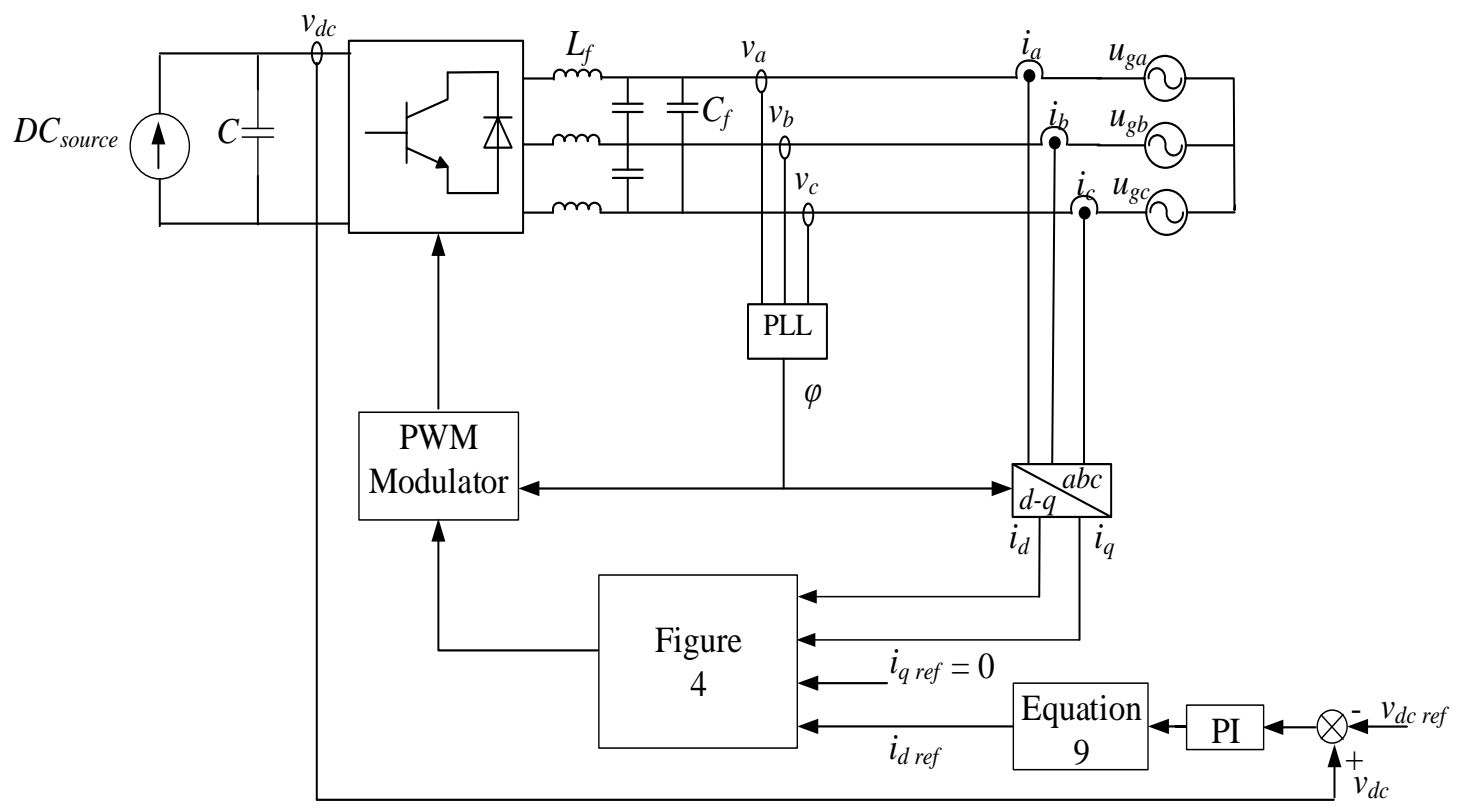

Figure 3. Interlinking converter

$$
i_{\text {dreff }}=\left\{\begin{array}{c}
i_{\text {dreff }} ;-C_{\min }<i_{\text {dreff }}<C_{\max } \\
-C_{\min } ; i_{\text {dreff }}<-C_{\min } \\
C_{\max } ; i_{\text {dreff }}>C_{\max }
\end{array}\right.
$$

As an input PWM modulator the values of $v_{d}$ and $v_{q}$ are the sum between $i_{d}$ and $i_{q}$ with $i_{d \text { reff }}$ and $i_{q \text { reff }}$ that controlled by the PI controler, as described in Figure 4. Finally, the PWM modulator produces pulses that move the switch on IGBTs in the interlinking converter. 


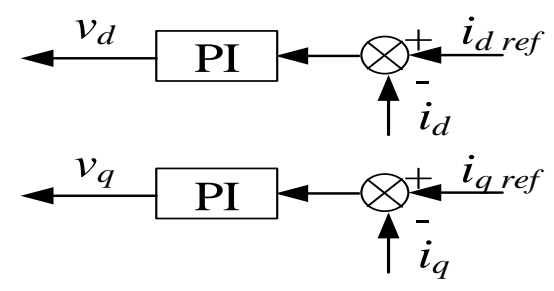

Figure 4. Current Regulator

\section{SIMULATION AND DISCUSSION}

Hybrid AC-DC microgrids are modeled by SIMULINK/MATLAB simulation. DC sub microgrid have 2 DC sources, 600 voltage, each connected with permanen load of $1 \mathrm{KW}$, while the power from the DC source will be set to determine the system response. Generator with 4MW capacity, 400V voltage, $50 \mathrm{~Hz}$ frequency, $\mathrm{R} / \mathrm{X}$ ratio 7 as a source in $\mathrm{AC}$ sub microgrid, connected with $1 \mathrm{MW}$ permanen load and $1 \mathrm{MW}$ as additional load. DC sub microgrid is connected to AC sub microgrid via an interlinking converter as shown in The simulation algorithm is started by setting the power source conditions in the DC sub microgrid as explained in Figure 5. With power changes in DC sub microgrid, the power flow that occurs in the system can be separated into two different cases, they are:

1. Power flow from DC to AC sub microgrids (IC in Inverter Mode).

2. Power flow from AC to DC sub microgrids (IC in Rectifier Mode).

Power flow analysis was carried out in two places, in the DC sub microgrid and AC sub microgrid (Figure 1).

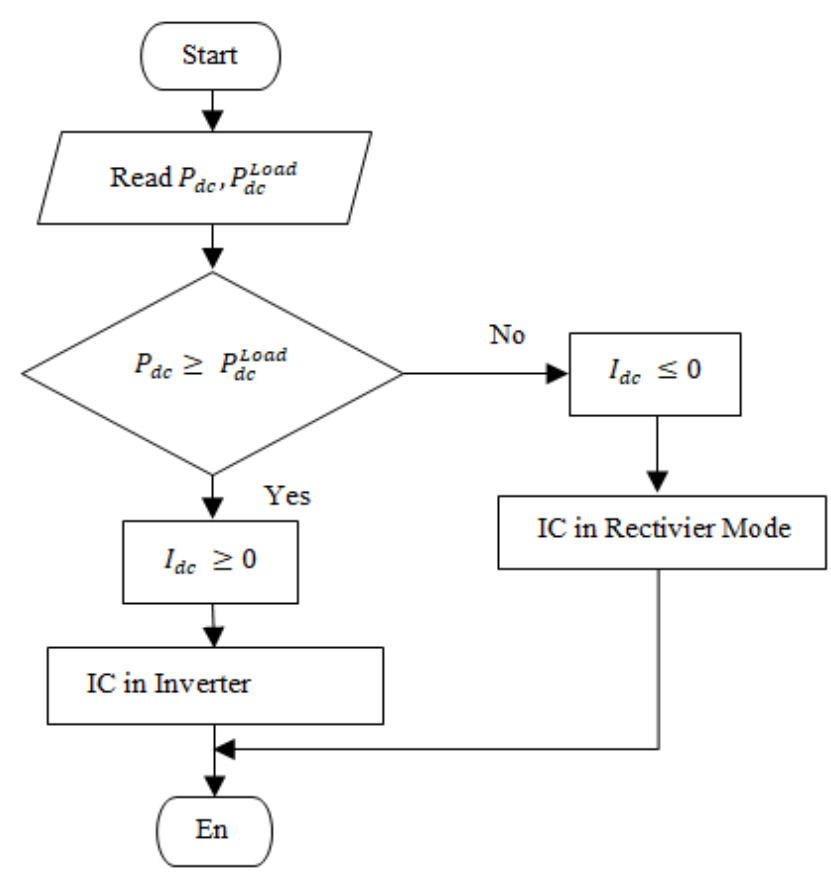

Figure 5 Simulation algorithm

\subsection{Power flow in DC sub microgrid}

In the first case, power flow from DC to AC sub microgrids, the power on the DC sub microgrids is set in $10 \mathrm{KW}$, in $\mathrm{t}=3 \mathrm{~s}$ then drops to $5 \mathrm{KW}$ and goes down again in $\mathrm{t}=4,5 \mathrm{~s}$ to just $1 \mathrm{KW}$. A decrease in power makes changes in the current direction, from DC sub microgrid to AC sub microgrid to vice versa. The change of current direction cause changes in power flow, the power flowing from positive 8 KW gradually down to negative $5 \mathrm{KW}$. In voltage, there is a little overshoot when the power change, but it is relatively stable. Greater overshoot occurs when there is a large load change in AC sub microgrid, but this does not cause changes in power flow direction. 
In the second case, the power on the DC sub microgrid is set in $1 \mathrm{KW}$, then rises to $5 \mathrm{KW}$ and rises again to reach $10 \mathrm{KW}$. This case is the opposite of the condition in the first case. The simulation starts with the condition of DC sub microgrid that lacks of power. Figures 6 and 7 describe the result of this simulation.

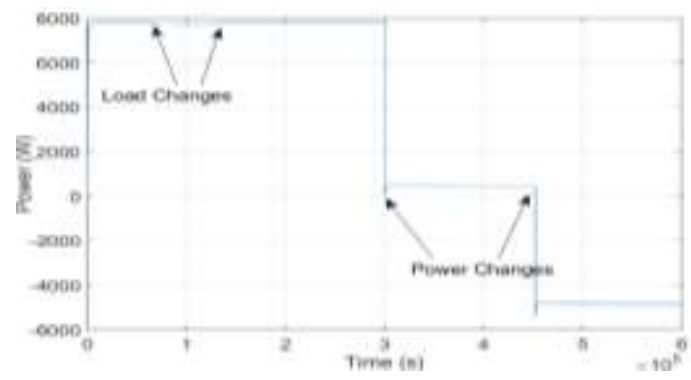

(a)

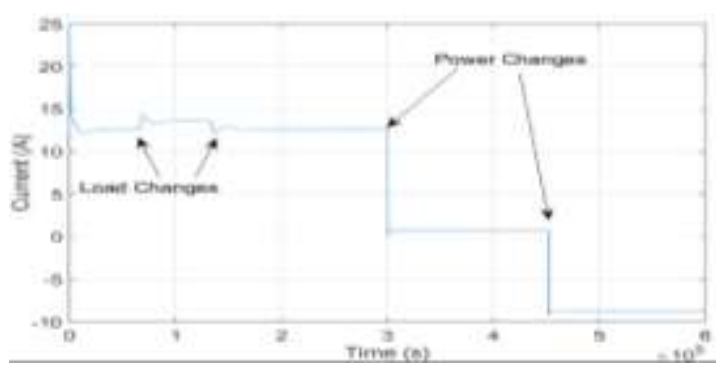

(b)

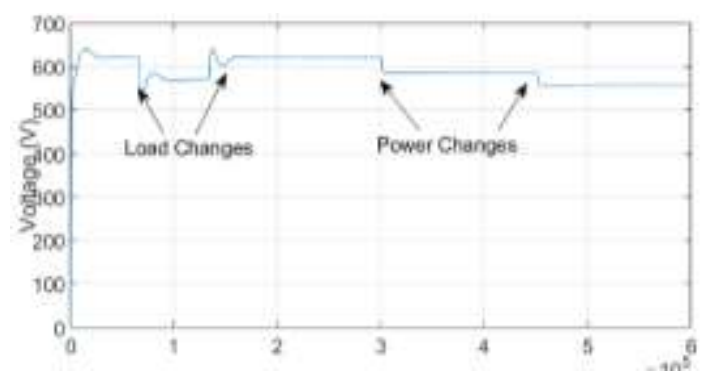

(c)

Figure 6. DC sub microgrid power, current and voltage in inverter mode, (a) Power, (b) Current, (c) Voltage

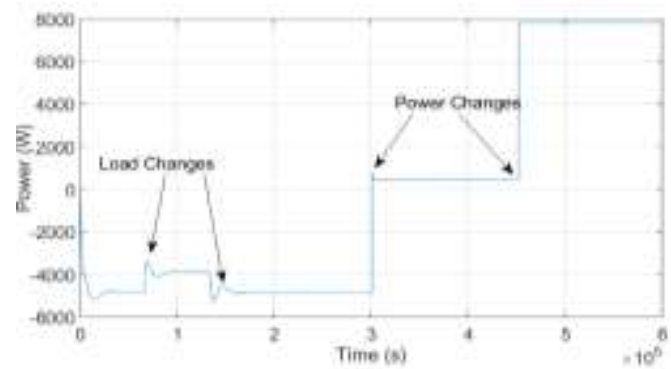

(a)

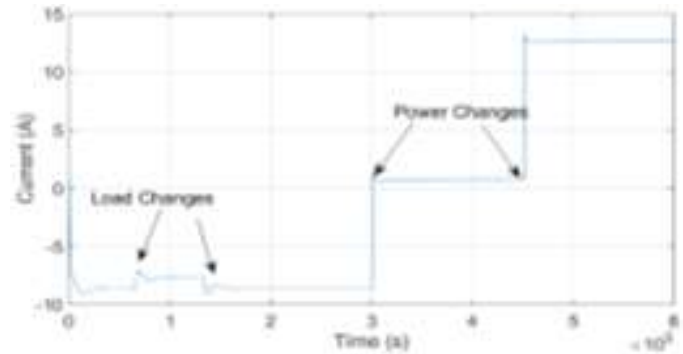

(b)

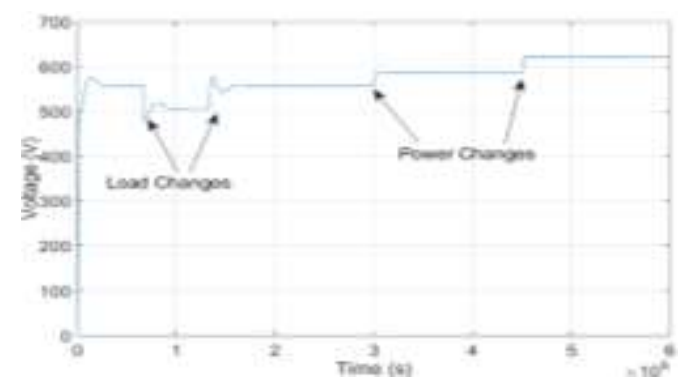

(c)

Figure 7. DC sub microgrid power, current and voltage in rectifier mode (a) Power, (b) Current, (c) Voltage

\subsection{Power flow in AC sub microgrid}

In the first case, the power flow on the AC sub-microgrid due to a decrease in power on the DC sub-microgrid can be seen in Figures 8, 9 and 10. In Figure 8(a), there is a voltage reaction combined with a current during the simulation. Change direction of power flow is indicated by an angular shift between current and voltage almost $90^{\circ}$ [13, 24-25]. Figures 8(b) and 8(c) are excerpts from Figure 8a which show the shift. Figure 9 describes the result of active and reactive power, and Figure 10 show the frequency that occurs in the AC sub microgrid.

The results of the second case are described in Figures 11, 12, and 13. As in the first case, the phase shift in current to voltage indicates a change in the direction of the power flow shown in Figures 11 and described in Figures 11 (a) and 11 (b). An increase or decrease in power causes a little overshoot on active power, reactive power, and frequency. Greater overshoot occurs due to additional load, but this does not change the power flow direction. 


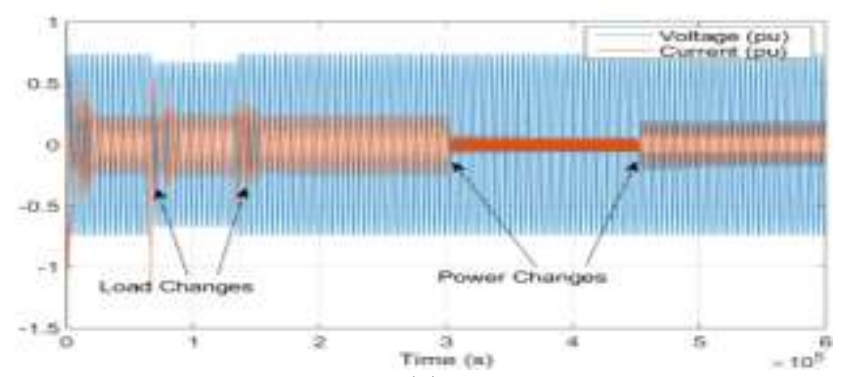

(a)

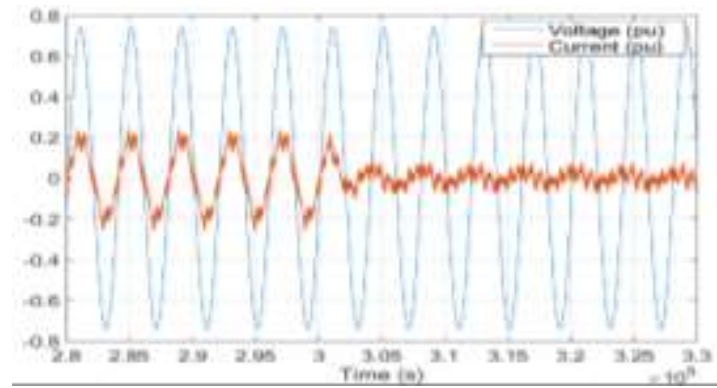

(b)

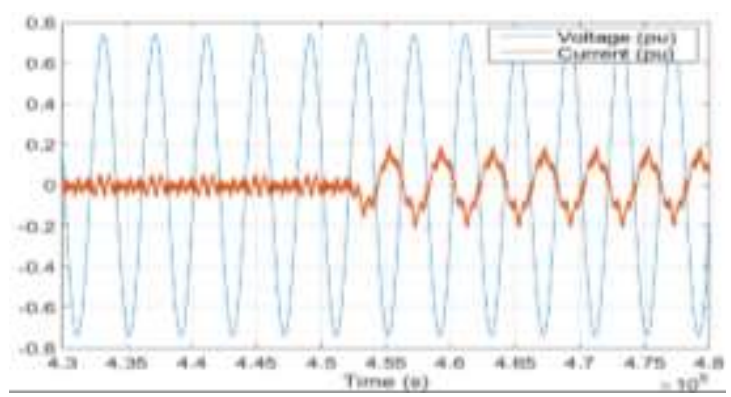

(c)

Figure 8. AC sub microgrid voltage and current in first case (a) The results of the whole simulation, (b) simulation at $\mathrm{t}=2.8 \mathrm{~s}$ to $\mathrm{t}=3.3 \mathrm{~s}$ (c) simulation at $\mathrm{t}=4.3 \mathrm{~s}$ to $4.8 \mathrm{~s}$

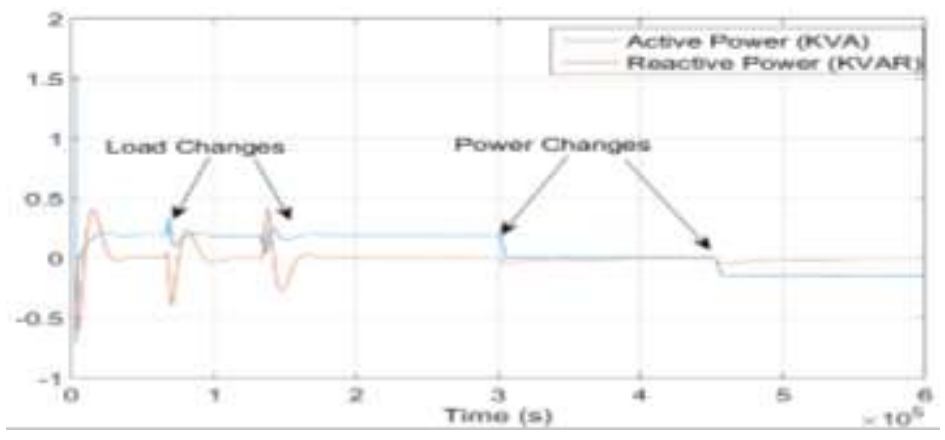

Figure 9. Active and reactive power in first case

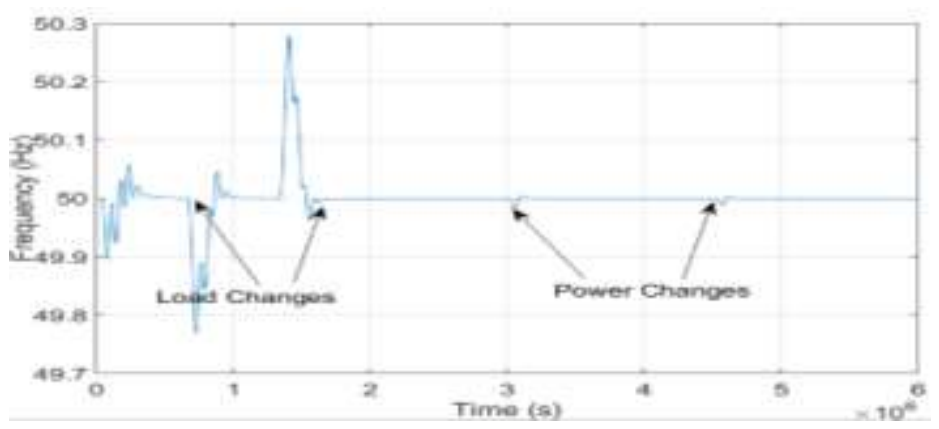

Figure 10. Frequency in first case 


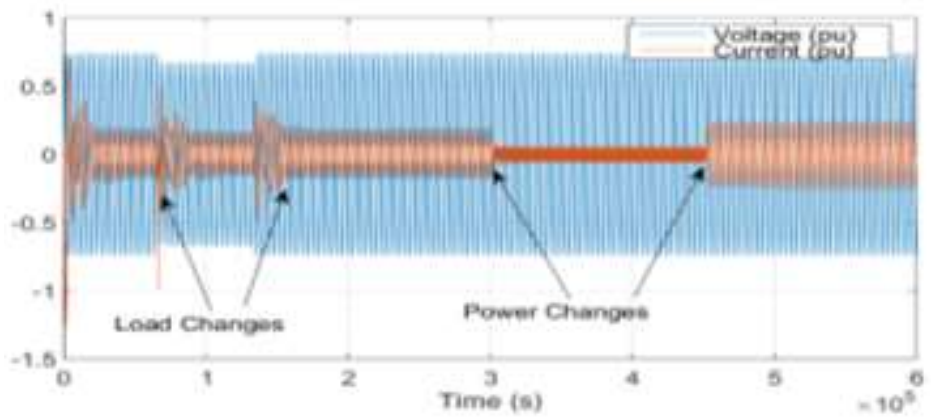

(a)

Figure 11. AC sub microgrid voltage and current in second case (a) The results of the whole simulation,

(b) simulation at $\mathrm{t}=2.7 \mathrm{~s}$ to $\mathrm{t}=3.3 \mathrm{~s}$, (c) simulation at $\mathrm{t}=4.3 \mathrm{~s}$ to $4.8 \mathrm{~s}$

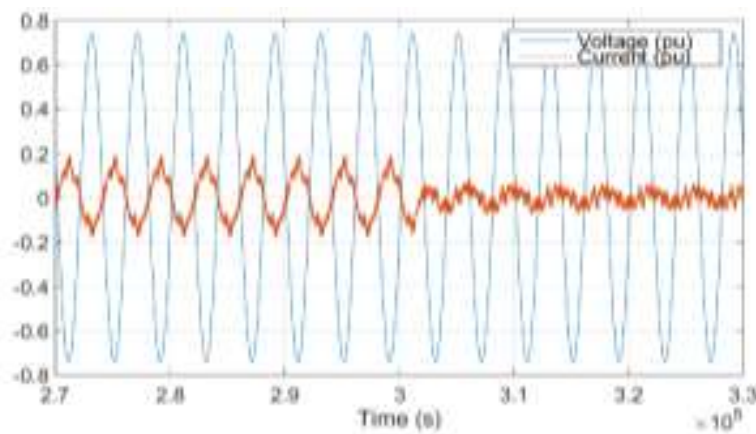

(b)

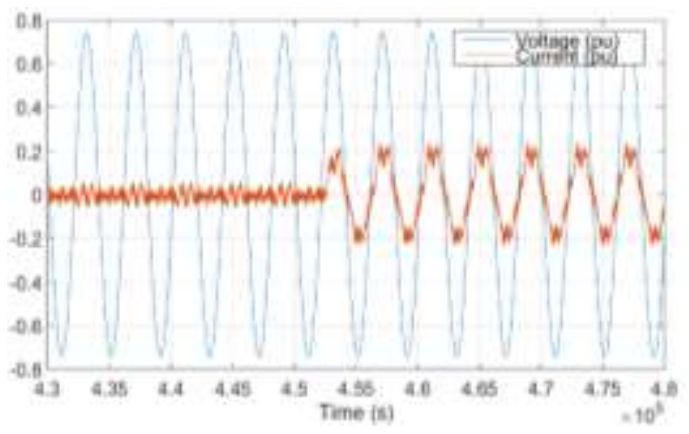

(c)

Figure 11. AC sub microgrid voltage and current in second case (a) The results of the whole simulation, (b) simulation at $\mathrm{t}=2.7 \mathrm{~s}$ to $\mathrm{t}=3.3 \mathrm{~s}$, (c) simulation at $\mathrm{t}=4.3 \mathrm{~s}$ to $4.8 \mathrm{~s}$

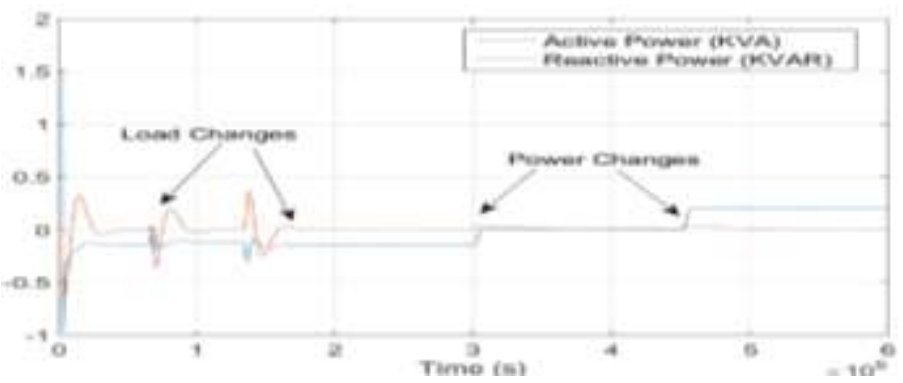

Figure 12. Active and reactive power in rectifier mode

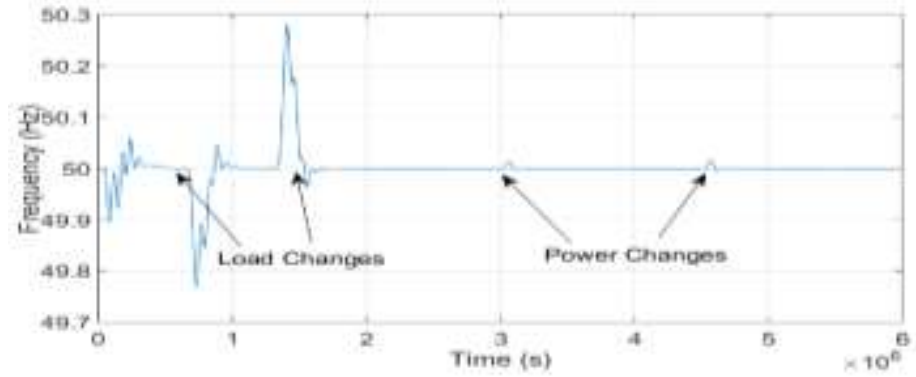

Figure 13. Frequency in rectifier mode 


\section{CONCLUSION}

This paper discusses the low voltage hybrid AC-DC microgrids power flow in islanding operation. The model simulation of hybrid AC-DC microgrid model have been carried out in two different cases, power flow from DC to AC sub microgrids and power flow from AC to DC sub microgrids. The result of the simulation shows that the model has a good response to power changes conditions. With the phase shift between current and voltage proves that the interlinking converter can flow the power, either active or reactive power from the dc sub microgrid to the ac sub microgrid and vice versa. In addition to power flow, interlinking converters can also keep the voltage and frequency system stable and reliable during load and power changes. Overall it can be said that the model can be simulated properly.

\section{ACKNOWLEDGEMENTS}

Firstly, the authors would like to pay their respectfully thanks to God, their beloved family, teachers and their admirer supervisor. Special thanks to the Directorate General of Higher Education of Republic of Indonesia. That has provided supporting and funding for this research.

\section{REFERENCES}

[1] Bambang Purwahyudi, Kuspijani, Ahmadi, "SCNN Based Electrical Characteristics of Solar Photovoltaic Cell Model," International Journal of Electrical and Computer Engineering (IJECE), Vol. 7, No. 6, pp. 3198-3206, December 2017

[2] Amirullah, Agus Kiswantono, Ontoseno Penangsang, Adi Soeprijanto, "Transient Power Quality Performance of Multi Photovoltaics using MPPT P and O / MPPT Fuzzy," TELKOMNIKA Telecommunicatio Computing and Control, Electronic, Vol. 16, No. 6, pp. 2967-2979, December 2018

[3] M. Reyasudin Basir Khan, Jagadeesh Pasupuleti, Jabbar Al-Fattah, Mehrdad Tahmasebi, " Optimal Grid-Connected PV System for a Campus Microgrid," International Journal of Electrical Engineering and Computer Science (IJEECS), Vol. 12, No. 3, pp. 899-906, December 2018

[4] Shahril Irwan Sulaiman, Nur Amira Ali, "Performance Simulation of The Integration of Hybrid Stand-Alone Photovoltaic System at Tuba Island," International Journal of Electrical Engineering and Computer Science (IJEECS), Vol. 16, No. 1, pp. 107-115, October 2019

[5] Xiong Liu, Peng Wang, Poh Chiang Loh, "A Hybrid AC/DC Microgrid and Its Coordination Control," IEEE Transaction On Smart Grid, Vol. 2, No. 2, pp. 278-286, Juni, 2011

[6] Hasti Afianti, Ontoseno Panangsang, Adi Soeprijanto, "Management Strategy of Hybrid Microgrid to Reduce Multiple Conversion," International Conference on Electrical Engineering, Informatics and Its Education 2015 (CEIE- 2015), Malang, Indonesia, October 3, 2015

[7] Mohammad Taufik, Taufik Taufik, " UNPAD's DC House Prototype to Showcase an Alternative Solution to Rural Electrification," International Conference on Rural Development and Community Empowerment, Bandung, Indonesia, November 2015

[8] Sung -Hwan Park, Jing Yon Choi, Dong-Jun Won, "Cooperative Control Between the Distributed Energy Resource in AC / DC Hybrid Microgrid," IEEE XPlore, Innovative Smart Grid Technologies Conference, 2014

[9] Navid Eghtedarpour, Ebrahim Farjah, "Power Control and Management in an AC/DC Hybrid Microgrid," IEEE Transaction On Smart Grid, Volume 5 Issue 3, pp. 1494-1505, 2014

[10] Xiong Liu, Peng Wang, Poh Chiang Loh, "A Hybrid AC/DC Micro-grid," 2010 Conference Proceedings IPEC, 2729 October 2010

[11] Bo Long, Taek Won Jeong, Jong Deuk Lee, Yoo Cheol Jung, Kil To Chong, "Energy Management of a Hybrid AC-DC Micro-Grid Based on a Battery Testing System," Energies, vol 8, pp. 1181-1194, 2015

[12] Hasti Afianti, Mochamad Ashari, Ontoseno Panangsang, Adi Soeprijanto, Suyanto, " Power Transfer Enhancement in Hybrid AC-DC Microgrids," Journal of Engineering and Applied Sciences, Vol. 11, No. 7, pp. 1660-1664, 2016

[13] Xiancheng Zheng, Fei Gao, Husan Ali, Huamei Liu, "A Droop Control Based Three Phase Bidirectional AC-DC Converter for More Electric Aircraft Applications," Energies, Volume 10, Issue 3, 2017

[14] Xiaochao Hou, Yao Sun, Wenbin Yuan, Hua Han, Chaolu Zhong, Josep M. Guerrero, "Conventional P- $\omega$ / Q-V Droop Control in Highly Resistive Line of Low-Voltage Converter-Based AC Microgrids," Energies, Volume 9, Issue 11, 2016

[15] Chendan Li, Sanjay K. Chaudhary, Mehdi Savaghebi, Juan C. Vasquez, Josep M. Guerrero, " Power Flow Analysis for Low-Voltage AC and DC Microgrids Considering Droop Control and Virtual Impedance," IEEE Transactions On Smart Grid, Vol. 8, No. 6, pp. 2754-2764, 2017

[16] K. De Brabandere, B. Bolsens, J. Van den Keybus, A. Woyte, J. Driesen, R. Belmans, " A Voltage and Frequency Droop Control Method for Parallel Inverters," IEEE for Transactions on Power Electronic, volume 22, issued 4, pp. 1107-1115, 2007

[17] H.M. El-Deeneb, M. I. Daoud, A. Elserougi, S Abdel-Khalik, S. Ahmed, A. M. Massoud., " Maximum Power flow of PV-Fed Inverter-Based Distributed Generation with Improved Voltage Regulation Using Flywheel Energy Storage Systems," IECON 2014, Dallas TX USA, 29 Okt-1 Nov 2014 
[18] N. Hamrouni, M.Jraidi, A. Cherif, "New Method of Current Control for LCL-Interfaced Grid - Connected Three Phase Voltage Source Inverter," Revue des Energies Renouvelables 13(1), 2010

[19] Gailan Abdul Qadir, Majid S. Naghmash, "Design and Simulation of Programmable AC-DC Converter Using Pulse Width Modulation (PWM) Techniques in MATLAB," International Journal of Soft Computing and Engineering (IJSCE), Vol. 3, Issue 6, ISSN: 2231-2307, January 2014

[20] Saidah, Bambang Purwahyudi, Kuspijani, "Control Strategy for PWM Voltage Source Converter Using Fuzzy Logic for Adjustable Speed DC Motor," International Journal of Power Electronics and Drive System (IJPEDS), Vol. 8, No. 1, pp. 51-58, March 2017

[21] Vellanki Mehar Jyothi, T. Vijay Muni, SVNL Lalitha, " An Optimal Energy Management System for PV/Battery Standalone System," International Journal of Electrical and Computer Engineering (IJECE), Vol. 6, No. 6, pp. 2538-2544, December 2016

[22] Azrita Alias, Nasrudin Abd. Rahim, Mohd Azlan Hussain, " Bidirectional Three Phase Power Converter," IEEE First Conference on Clean Energy and Technology CET, 2011

[23] Lili Huang, Lili Huang, Xin Chen, Lan Xiao, Chunying Gong, , "Research on the Bi-Directional AC-DC Converter for the Large Non-Grid-Connected Wind Power Application," 2009 World Non-Grid-Connected Wind Power Energy Conference, 2009

[24] Poh Chiang Loh, Ding Li, Yi Kang Chai, and Frade Blaabjerg, " Autonomous Operation of Hybrid Microgrid With AC and DC Subgrids," IEEE Transaction on Power Electronics, Vol 28, No. 5, pp. 2214 - 2223, May 2013

[25] Poh Chiang Loh, Ding Li, Yi Kang Chai, and Frade Blaabjerg,"Autonomous Control of Interlinking Converter With Energy Storage in Hybrid AC-DC Microgrid," IEEE Transaction on Industry Applications, Vol 4, No. 3, pp. 1374-1382, May/June 2013

\section{BIOGRAPHIES OF AUTHORS}

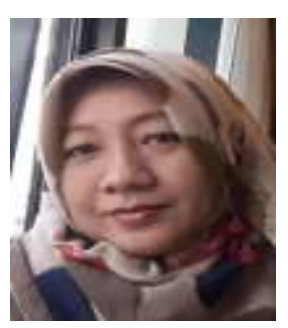

Hasti Afianti was born in Surabaya East Java Indonesis, in 1974. She received bachelor and master degree in electrical engineering from ITS Surabaya, in 1998 and 2005, respectively. She also worked as a lecturer in University of Bhayangkara Surabaya. She is currently working toward the doctoral degree, in electrical engineering in Power System and Simulation Laboratory (PSSL) ITS Surabaya. Her research interest includes power system modeling and simulation, microgrid, power quality, distribution automation system and renewable energy.

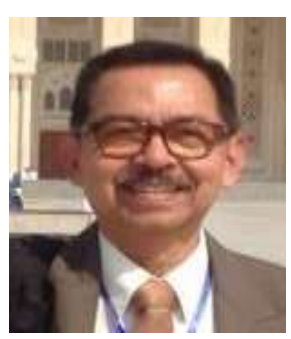

Ontoseno Penangsang was born in Madiun East Java Indonesia, in 1949. He received bachelor degree in electrical engineering from ITS Surabaya, in 1974. He received M.Sc and Ph.D degree in Power System Analysis from University of Wisconsin, Madison, USA, in 1979 and 1983, respectively. He is currently a professsor at Department of Electrical Engineering and the Head of Power System and Simulation Laboratory (PSSL) ITS Surabaya. He has a long experience and main interest in power system analysis (with renewable energy sources), design of power distribution, power quality, and harmonic migitation in industry.

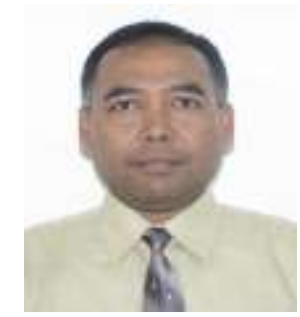

Adi Soeprijanto was born in Lumajang East Java Indonesia, in 1964. He received bachelor in electrical engineering from ITB Bandung, in 1988. He received master of electrical engineering in control automatic from ITB Bandung. He continued his study to Doctoral Program in Power System Control in Hiroshima University Japan and was finished in 2001. He is currently a professsor at Department of Electrical Engineering and member of Power System and Simulation Laboratory (PSSL) in ITS Surabaya. His main interest includes power system analysis, power system stability control, and power system dynamic stability. He had already achieved a patent in optimum operation of power system. 